\title{
CRESCIMENTO E PRODUÇÃO DE HASTES FLORAIS DE GLADÍOLO CULTIVADO SOB DIFERENTES TENSÕES DE ÁGUA NO SOLO ${ }^{1}$
}

\author{
Growth and production of gladiolus floral stems under different soil water tensions
}

\author{
Joelma Rezende Durão Pereira ${ }^{2}$, Jacinto de Assunção Carvalho ${ }^{3}$, Patrícia Duarte de Oliveira Paiva ${ }^{4}$, \\ Douglas José da Silva ${ }^{5}$, Alexandre Márcio Gomes de Souza ${ }^{6}$, Kleber Junio de Souza ${ }^{7}$
}

\begin{abstract}
RESUMO
As plantas ornamentais, em geral, e o gladíolo, em particular, são bastante suscetíveis às variações do nível de água no solo. No presente estudo foram avaliados os efeitos de diferentes níveis de tensão de água no solo sobre o crescimento e produção do gladíolo, em experimento realizado em casa-de-vegetação em Lavras, Minas Gerais. Esses efeitos foram caracterizados nas fases de crescimento vegetativo, espigamento e floração, por análises das seguintes medidas de crescimento: altura da planta, tamanho da haste floral e número de flores. O delineamento experimental foi o inteiramente casualizado em esquema de faixas, avaliando-se quatro níveis de tensão de água no solo $(15,25,40$ e $60 \mathrm{kPa})$ em cada uma das três fases fenológicas da cultura, totalizando doze tratamentos e seis repetições. Os resultados mostraram que a altura da planta, tamanho da haste floral e o número de flores foram significativamente reduzidos pelo aumento dos níveis de tensão de água no solo, sendo os efeitos mais intensos nas fases de crescimento e espigamento. Os melhores resultados em relação ao tamanho da planta, da haste floral e número de flores, foram obtidos mantendo-se a tensão de água no solo próxima à capacidade de campo.
\end{abstract}

Termos para indexação: Gladiolus x grandiflorus, irrigação, análise de crescimento.

\begin{abstract}
The ornamental plants in general, and specially the gladiolus, are susceptible to variations of the soil water level. The effects of different soil water tensions on growth and production of gladiolus were evaluated in an experiment carried out in a greenhouse located in Lavras, Minas Gerais State, Brazil. These effects were characterized during the stages of vegetative growth, pre-flowering and flowering by analyzing plant height, floral stem length and number of flowers. The experimental design was completely randomized in a strip outline of four levels of soil water tensions $(15,25,40$ and $60 \mathrm{kPa})$ on each growth stage, totalizing twelve treatments and six replications. The results demonstrated that plant height, floral stem length and number of flowers were reduced by increasing the levels of soil water tension with higher effects during the stages of vegetative growth and pre-flowering. The best results in terms of plant size, length of the floral stem and number of flowers were obtained maintaining the level of soil water tension close to the field capacity.
\end{abstract}

Index terms: Gladiolus x grandiflorus, irrigation, growth analysis.

(Recebido em 20 de setembro de 2005 e aprovado em 24 de março de 2006)

\section{INTRODUÇÃO}

O setor da floricultura no Brasil é apontado como uma das melhores alternativas para quem busca investimento na agricultura, isto porque demanda pequenas áreas e o ciclo de produção, dependendo da cultura, é geralmente curto, o que permite giro rápido de capital (Matsunaga, 1995).

Estudo desenvolvido na Universidade Federal de Lavras verificou que o gladíolo (Gladiolus x grandiflorus
L.) representa uma alternativa como cultura intercalar à lavoura cafeeira, pois sua época de cultivo coincide com um período de poucas atividades na lavoura, além do bom retorno financeiro que pode ser obtido quando cultivado em pequenas áreas (Paiva et al., 2000).

De forma geral, os gladíolos são plantas bastante sensíveis à deficiência hídrica, principalmente às grandes variações do conteúdo de água no solo, refletindo-se num desenvolvimento precário e desuniforme do produto final.

\footnotetext{
${ }^{1}$ Parte da tese de doutorado desenvolvida pela primeira autora.

²Engenheira Agrícola, Doutora em Irrigação e Drenagem - Unidade de Gestão da Educação Presencial/GEDUP, Engenharia de Produção - Centro Universitário do Sul de Minas/UNIS - Av. Coronel José Alves, 256, Bairro Vila Pinto - 37010-540 - Varginha, MG - jodurao@oi.com.

3Engenheiro Agrícola, Doutor - Engenharia - Universidade Federal de Lavras/UFLA - Cx. P. 3037 - 37200-000 - Lavras, MG - jacintoc@ufla.br ${ }^{4}$ Engenheira Agrônoma, Doutora - Agricultura - Universidade Federal de Lavras/UFLA - Cx. P. 3037 - 37200-000 - Lavras, MG - pdolivei@ufla.br ${ }^{5}$ Engenheiro Agrônomo - Departamento de Irrigação - Fênix Agro Industrial LTDA -Rod. Cornélio Pires, Km 69,5 - 18530-000 - SP 127 - Tiête, SP dosmig@hotmail.com

${ }^{6}$ Engenheiro Agrícola - Unidade Universitária de Ciências Exatas - Universidade Estadual de Goiás/UEGO - Br 153, Km 98 - Arco Verde -75001970 Anápolis

${ }^{7}$ Engenheiro Agrícola - Assistência Técnica - Industria Machina ZaccariaS/A - R: Laranjal,180, Vila Fachina - 13484-016 - Limeira, SP _ kleberhalwai@yahoo.com.br
} 
Para o gladíolo, a deficiência no fornecimento de água prejudica o desenvolvimento vegetativo e florescimento, formando inflorescências com comprimento reduzido. A falta de água pode provocar queima na ponta das espigas e apressar o ciclo, enquanto que o excesso pode causar retardamento do ciclo e até apodrecimento dos bulbos. Durante as fases de desenvolvimento e floração, o gladíolo é bastante exigente em água, devendo a umidade do solo estar próxima a capacidade de campo (Paiva et al., 1999; Carvalho et al., 2001).

Carvalho et al. (2001) avaliaram os efeitos de diferentes níveis de déficit hídrico sobre o crescimento e produção do gladíolo. Os níveis de déficit hídrico foram estabelecidos em função da reposição da água consumida diariamente. Para cada fase fenológica foram aplicados os seguintes tratamentos de déficit hídrico: 0, 20, 40 e 60\%. O trabalho foi realizado em casa-de-vegetação, sendo os gladíolos produzidos em vasos de 13 litros. Os autores concluíram que com o aumento do déficit hídrico o tamanho da haste floral e o número de flores foram afetados quando este ocorreu, primeiramente, na fase de espigamento seguida da fase de crescimento.
Conduziu-se este trabalho, com o objetivo de avaliar a resposta de parâmetros de crescimento e produção de hastes florais de gladíolo à aplicação de diferentes tensões de água no solo em três fases de desenvolvimento do gladíolo.

\section{MATERIALE MÉTODOS}

$\mathrm{O}$ experimento foi realizado no período de março a maio de 2004, conduzido em casa-de-vegetação localizada em Lavras, MG, à $21^{\circ} 14^{\prime} \mathrm{S}$ de latitude e a $45^{\circ} 00^{\prime} \mathrm{W}$ de longitude, a uma altitude de 918 metros. O solo da área experimental foi classificado como Latossolo Vermelho Distroférrico (Tabela 1). As temperaturas médias máxima e mínima foram de $31^{\circ} \mathrm{C}$ e $17^{\circ} \mathrm{C}$, respectivamente, e as umidades médias máxima e mínima foram de $96 \%$ e $50 \%$, respectivamente.

O delineamento experimental foi de blocos casualizados em esquema de faixas, com seis repetições. Analisou-se o efeito de quatro tensões de água no solo, em três fases de desenvolvimento da cultura, totalizando doze tratamentos e setenta e duas parcelas, tendo cada parcela as dimensões de 1,00 x 1,05 m, com 60 plantas, das quais considerou-se como úteis as 10 plantas centrais, de acordo com o croqui mostrado na Figura 1.

Tabela 1 - Resultados da análise física do solo da área experimental, UFLA, Lavras/MG, 2005.

\begin{tabular}{|c|c|c|c|c|c|}
\hline \multirow[t]{2}{*}{$\begin{array}{l}\text { Camada } \\
(\mathrm{cm})\end{array}$} & \multicolumn{3}{|c|}{$\begin{array}{c}\text { Análise Textural } \\
(\mathrm{dg} / \mathrm{kg})\end{array}$} & \multirow[t]{2}{*}{$\begin{array}{c}\operatorname{Dg}^{1} \\
\left(\mathrm{~g} / \mathrm{cm}^{3}\right)\end{array}$} & \multirow[t]{2}{*}{$\begin{array}{c}\mathrm{Dg}^{2} \\
\left(\mathrm{~g} / \mathrm{cm}^{3}\right) \\
\end{array}$} \\
\hline & Areia & Limo & Argila & & \\
\hline $0-20$ & 9 & 44 & 47 & 1,01 & 2,74 \\
\hline $20-40$ & 9 & 18 & 73 & 1,00 & 2,70 \\
\hline
\end{tabular}

${ }^{1}$ Densidade global do solo; ${ }^{2}$ Densidade das partículas do solo.
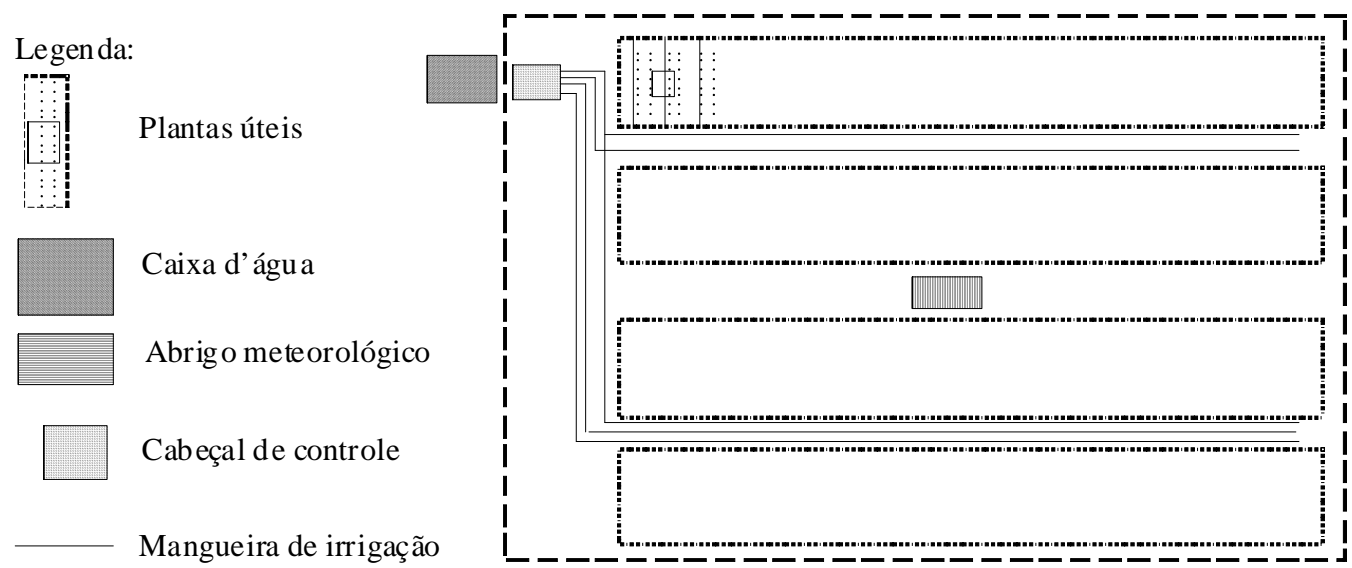

Figura 1 - Croqui da área experimental, mostrando a distribuição das parcelas no esquema em faixas e equipamentos para controle da irrigação. 
Após o plantio dos bulbos de gladíolo da cultivar White Goddess, realizaram-se irrigações uniformes, com uso de microaspersores, em todos os canteiros para um adequado estabelecimento da cultura. Vinte dias após o transplantio deu-se início aos tratamentos.

A irrigação utilizada nos tratamentos foi a localizada, por gotejamento, sendo as linhas de gotejo inseridas entre as linhas de plantio em cada parcela. Cada linha continha três gotejadores espaçados de 0,35 m com vazão média de $2 \mathrm{~L} / \mathrm{h}$ à pressão de $20 \mathrm{kPa}$.

Para avaliar os efeitos das tensões de 15, 25, 40 e 60 $\mathrm{kPa}$, a irrigação foi monitorada com uma bateria de três tensiômetros, instalados na profundidade de $0,10 \mathrm{~m}$ com três repetições para cada tratamento da irrigação. Quando pelo menos dois tensiômetros indicavam o valor da tensão do tratamento correspondente, aplicava-se a irrigação até elevar o solo à capacidade de campo, $10 \mathrm{kPa}$, que foi determinada por testes feito no local do experimento. A duração da irrigação correspondeu ao tempo necessário para elevar a umidade do solo à capacidade de campo, variando de acordo com cada tratamento: 10, 35, 48 e 55 minutos para as tensões de 15, 25, 40 e $60 \mathrm{kPa}$, respectivamente. As leituras foram monitoradas duas vezes ao dia, às 08 hs e às 16 hs.

As fases fenológicas de crescimento, espigamento e florescimento foram caracterizadas da seguinte forma: o final do estádio vegetativo e início do estádio de espigamento foi estabelecido quando pelo menos $50 \%$ das plantas apresentaramse no início de formação da espiga floral na base da planta. $\mathrm{O}$ final do estádio de espigamento e início do estádio de florescimento caracterizou-se quando pelo menos $50 \%$ das plantas apresentaram o início da abertura da inflorescência.

Durante o período (fase fenológica) em que as parcelas não se encontravam submetidas aos tratamentos de tensão de água no solo, realizava-se a irrigação com a tensão de $15 \mathrm{kPa}$.

Ao final do experimento, fez-se a coleta dos dados correspondentes às medidas de altura de plantas, tamanho da haste floral e número de flores. A classificação das plantas foi realizada segundo o Padrão da Cooperativa Holambra (Paiva et al., 1999).
As médias dos dados foram comparadas pelo teste Scott-Knott, tendo sido obtidas também equações de regressão do fator tensão testado e as medidas de crescimento de produção.

\section{RESULTADOS E DISCUSSÃO}

Os resultados mostrados pela Tabela 2 revelam que as fases de crescimento (desenvolvimento vegetativo da cultura) e espigamento (início de emissão da inflorescência) foram os períodos mais sensíveis à redução dos níveis de umidade do solo (equivalente à elevação dos valores de tensão de água no solo), pois essas fases apresentaram os menores valores das medidas de crescimento.

Carvalho et al. (2001) observaram o mesmo comportamento da cultura do gladíolo e verificaram que a fase mais sensível à deficiência hídrica foi a de espigamento da cultura.

Com o aumento dos níveis de tensão de água no solo, observou-se influência linear e negativa para a altura da planta, para todas as fases. No entanto, para a fase de florescimento a inclinação da reta não é tão acentuada, uma vez que, durante as fases vegetativa e espigamento, as plantas não sofreram restrição de água no solo, pois sempre foram irrigadas a um nível de tensão de $15 \mathrm{kPa}$ e a fase em que foi aplicada o tratamento teve duração de apenas 7 dias (Tabelas 2 e 3).

Ainda verifica-se na Tabela 3 , que as plantas cultivadas sob maiores tensões durante a fase de crescimento e espigamento apresentaram menores alturas em relação àquelas em que a umidade do solo $(15 \mathrm{kPa})$ mantinha-se próxima à capacidade de campo (10 kPa). Consequentemente, a qualidade do produto final também foi inferior. As diferenças, entre as alturas, puderam ser observadas a partir do final destas fases, perdurando até o final do ciclo, mesmo sendo modificada a tensão durante as fases posteriores. A menor frequência da irrigação, durante as fases de crescimento e espigamento afetou a altura da planta de forma irreversível. Esta mesma observação foi feita por Farias et al. (2004), analisando o efeito do déficit hídrico na cultura do crisântemo, obtendo maior e menor porcentagem de vasos de alta qualidade irrigando a tensões de 4 e $30 \mathrm{kPa}$, respectivamente.

Tabela 2 - Valores médios de altura da planta, comprimento da haste e número de flores, nas diferentes fases da cultura do gladíolo em que foram aplicados os tratamentos de tensão de água no solo.

\begin{tabular}{ccccc}
\hline $\begin{array}{c}\text { Fases } \\
\text { Fenológicas }\end{array}$ & $\begin{array}{c}\text { Duração das fases } \\
(\text { dias })\end{array}$ & $\begin{array}{c}\text { Altura da Planta } \\
(\mathrm{cm})\end{array}$ & $\begin{array}{c}\text { Comprimento da } \\
\text { Haste }(\mathrm{cm})\end{array}$ & $\begin{array}{c}\text { Número de } \\
\text { Flores }\end{array}$ \\
\hline Florescimento & 7 & $96,4 \mathrm{a}$ & $116,4 \mathrm{a}$ & $13,3 \mathrm{a}$ \\
Crescimento & 42 & $78,7 \mathrm{~b}$ & $94,6 \mathrm{~b}$ & $9,0 \mathrm{~b}$ \\
Espigamento & 31 & $73,1 \mathrm{c}$ & $87,8 \mathrm{~b}$ & $9,0 \mathrm{~b}$ \\
\hline Média geral & - & 82,7 & 99,6 & 10,4 \\
CV $(\%)$ & - & 9,6 & 17,0 & 11,6 \\
\hline
\end{tabular}

Médias seguidas pela mesma letra nas colunas não diferem entre si pelo teste Scott-Knott a 1\%, de probabilidade. 
Maiores alturas de plantas foram obtidas quando as irrigações foram aplicadas a $15 \mathrm{kPa}$, independentemente da fase de desenvolvimento. As fases de crescimento e espigamento mostraram-se mais sensíveis à variação de tensão de água no solo, especialmente para maiores valores desse fator.

Quanto ao comprimento da haste, para todas as fases fenológicas, verificou-se que mantendo a tensão de água no solo próxima à capacidade de campo $(10 \mathrm{kPa})$, obtém-se maiores comprimentos de hastes, indicando que irrigações mais frequentes são mais indicadas. Observouse que, com o aumento da tensão de água no solo, o gladíolo respondeu negativamente no seu desenvolvimento, ou seja, o comprimento da haste reduziu até $45,8 \mathrm{~cm}$ para tensão de $60 \mathrm{kPa}$, não havendo classificação comercial para este valor (Tabelas 4 e 6). Observou-se, também, que em algumas plantas, não houve a formação da haste floral, permanecendo apenas na fase vegetativa, indicando a sensibilidade da cultura em relação à água.

O comportamento do número de flores foi influenciado pelos níveis de tensão de água no solo. Irrigações com menores níveis de tensão de água proporcionaram plantas com maior número de flores (Tabela 5).
Observou-se que, para os maiores níveis de tensão, 40 e $60 \mathrm{kPa}$, principalmente para a tensão de $60 \mathrm{kPa}$, algumas plantas apresentaram "abortamento" das inflorescências, chegando as mesmas a nem desenvolverem ou abrirem. De acordo com Paiva et al. (1999), a deficiência no fornecimento de água prejudica o desenvolvimento vegetativo e o florescimento, formando inflorescências com comprimento reduzido.

Irrigações mais frequentes, aplicadas a tensões de $15 \mathrm{kPa}$, anteciparam a abertura das inflorescências, ocorrendo próxima dos 65 dias após plantio (DAP). Irrigações frequentes em condições de temperatura adequada podem proporcionar precocidade à produção de flores.

A classificação da qualidade em que se enquadram os gladíolos foi feita baseando-se no Padrão de Classificação da Cooperativa Holambra (Paiva et al., 1999). Pela Tabela 6, analisando os fatores recomendados pelo padrão de classificação, observou-se que 33\% das hastes florais do gladíolo enquadraram-se na classificação extra, para a fase de florescimento, demonstrando que a maior disponibilidade de água no solo (baixas tensões) para a cultura nessa fase é fator limitante em relação à qualidade dos produtos.

Tabela 3 - Altura média das plantas (H), nas fases de crescimento, espigamento e florescimento, da cultura do gladíolo, em função dos níveis de tensão de água no solo (T).

\begin{tabular}{ccc}
\hline Fase & Equação & $\mathrm{R}^{2}$ \\
\hline Crescimento & $\mathrm{H}=-1,2069 \mathrm{~T}+120,93$ & 0,9939 \\
Espigamento & $\mathrm{H}=-1,1229 \mathrm{~T}+112,45$ & 0,982 \\
Florescimento & $\mathrm{H}=-0,2283 \mathrm{~T}+104,39$ & 0,9841 \\
\hline
\end{tabular}

Tabela 4 - Comprimentos médios da haste floral (C) nas fases de crescimento, espigamento e florescimento, da cultura do gladíolo em função dos níveis de tensão de água no solo (T).

\begin{tabular}{ccc}
\hline Fase & Equação & $\mathrm{R}^{2}$ \\
\hline Crescimento & $\mathrm{C}=-1,5626 \mathrm{~T}+149,27$ & 0,9615 \\
Espigamento & $\mathrm{C}=-1,5657 \mathrm{~T}+142,85$ & 0,9881 \\
Florescimento & $\mathrm{C}=-0,2278 \mathrm{~T}+124,40$ & 0,9845 \\
\hline
\end{tabular}

Tabela 5 - Número médio de flores $(\mathrm{N})$ das plantas nas fases de crescimento, espigamento e florescimento, do gladíolo em função dos níveis de tensão de água no solo (T).

\begin{tabular}{ccc}
\hline Fase & Equação & $\mathrm{R}^{2}$ \\
\hline Crescimento & $\mathrm{N}=-0,2330 \mathrm{~T}+17,182$ & 0,9634 \\
Espigamento & $\mathrm{N}=-0,2539 \mathrm{~T}+17,912$ & 0,9881 \\
Florescimento & $\mathrm{N}=-0,0870 \mathrm{~T}+16,293$ & 0,9738 \\
\hline
\end{tabular}

Ciênc. agrotec., Lavras, v. 33, n. 4, p. 965-970, jul./ago. 2009 
Tabela 6 - Valores médios dos parâmetros comerciais em função das diferentes fases da cultura (C -crescimento; E espigamento; F - florescimento) e dos tratamentos de tensão de água no solo.

\begin{tabular}{|c|c|c|c|c|c|}
\hline Fase Fenológica & $\begin{array}{c}\text { Tensão de água } \\
\text { no solo }(\mathrm{kPa})\end{array}$ & $\begin{array}{l}\text { Tamanho da } \\
\text { Haste }(\mathrm{cm})\end{array}$ & Número de Flores & Classificação & $\begin{array}{c}\text { Percentagem } \\
\text { da classificação } \\
(\%)\end{array}$ \\
\hline $\mathrm{C}$ & 15 & 121,3 & 13,0 & I & 100 \\
\hline \multirow[t]{2}{*}{$\mathrm{C}$} & \multirow{2}{*}{25} & \multirow{2}{*}{110,5} & \multirow{2}{*}{11,4} & $\mathrm{I}$ & 50 \\
\hline & & & & II & 50 \\
\hline C & 40 & 95,3 & 9,1 & II & 100 \\
\hline $\mathrm{C}$ & 60 & 50,7 & 2,5 & Refugo & 100 \\
\hline $\mathrm{E}$ & 15 & 115,9 & 13,8 & I & 100 \\
\hline \multirow[t]{2}{*}{$\mathrm{E}$} & \multirow{2}{*}{25} & \multirow{2}{*}{106,4} & \multirow{2}{*}{11,3} & I & 50 \\
\hline & & & & II & 50 \\
\hline $\mathrm{E}$ & 40 & 83,3 & 8,9 & II & 100 \\
\hline $\mathrm{E}$ & 60 & 45,8 & 2,1 & Refugo & 100 \\
\hline \multirow[t]{2}{*}{$\mathrm{F}$} & \multirow{2}{*}{15} & \multirow{2}{*}{120,7} & \multirow{2}{*}{14,7} & Extra & 33 \\
\hline & & & & I & 67 \\
\hline $\mathrm{F}$ & 25 & 118,6 & 15,5 & I & 100 \\
\hline \multirow[t]{2}{*}{$\mathrm{F}$} & \multirow{2}{*}{40} & \multirow{2}{*}{116,1} & \multirow{2}{*}{12,8} & I & 67 \\
\hline & & & & II & 33 \\
\hline \multirow[t]{2}{*}{$\mathrm{F}$} & \multirow{2}{*}{60} & \multirow{2}{*}{110,3} & \multirow{2}{*}{11,2} & I & 50 \\
\hline & & & & II & 50 \\
\hline
\end{tabular}

Ainda na Tabela 6, observa-se que houve maior percentagem de hastes florais com a classe de qualidade I nos tratamentos em que a tensão de água no solo de $15 \mathrm{kPa}$ mantinha-se próxima à capacidade de campo. Exceção é feita para os tratamentos aplicados durante a fase de florescimento, pois esta não representa a fase crítica para a cultura, uma vez que está relacionada apenas com a abertura das inflorescências e não com a formação. $\mathrm{O}$ período em que os tratamentos foram aplicados nesta fase foi muito curto, de apenas 7 dias. Carvalho et al. (2001) verificaram o mesmo comportamento para a cultura do gladíolo, em que as melhores classes de qualidade, em todas as fases, foram obtidas quando se permitiu menores déficits hídricos na cultura. No tratamento de $15 \mathrm{kPa}$, as plantas atingiram classe de qualidade I (fase de crescimento e espigamento) e classe extra (florescimento) atingindo desta forma maior valor comercial.

Verifica-se, ainda, pela Tabela 6, que com o aumento da tensão de água no solo as hastes de gladíolo atingem classes de qualidade inferiores. Para as fases de crescimento e espigamento, com a tensão de $25 \mathrm{kPa}, 50 \%$ das hastes apresentaram-se na classe I e outros $50 \%$ na classe II. Observou-se apenas plantas com tamanho reduzido e menor número de flores, não apresentando danos às folhas e inflorescências.

Já para a tensão de $40 \mathrm{kPa}, 100 \%$ das hastes florais foram classificadas com a classe II. Nestes casos observaram-se plantas com enrugamento nas folhas, folhas enroladas e com as pontas queimadas. Algumas hastes florais, além do tamanho reduzido, apresentaram o abortamento das inflorescências para a tensão de $40 \mathrm{kPa}$.

A severidade do tratamento pode ser observada para a tensão de $60 \mathrm{kPa}$, em que $100 \%$ das hastes florais para as fases de crescimento e espigamento apresentaram a classificação de refugo. Neste caso, em algumas plantas de gladíolo não houve a formação da haste floral, e nas poucas plantas em que estavam presentes, observou-se o abortamento das inflorescências.

Observou-se de forma geral, que para os tratamentos com os maiores níveis de tensão, 40 e $60 \mathrm{kPa}$, as plantas apresentaram queimadura na ponta da parte aérea e enrugamento de algumas folhas. Isto é consequência direta do efeito da menor frequência da irrigação, uma vez que análises não indicaram falta de nenhum nutriente. 


\section{CONCLUSÕES}

As fases de crescimento e espigamento foram as mais afetadas pelo aumento dos níveis de tensão de água no solo, sendo o tamanho da haste formada, o número de flores e a altura das plantas de gladíolos inversamente proporcional a estes níveis;

Para a maior tensão, de $60 \mathrm{kPa}$, o tamanho médio da haste não atingiu classificação comercial, indicando a sensibilidade da cultura à menores conteúdos de água no solo.

A melhor qualidade do gladíolo foi conseguida quando as irrigações eram aplicadas de forma a não permitir que a tensão de água no solo ultrapasse o limite de $15 \mathrm{kPa}$, próximo à capacidade de campo.

\section{AGRADECIMENTOS}

À FAPEMIG - Fundação de Amparo à Pesquisa do Estado de Minas Gerais, pelo suporte financeiro deste projeto.

\section{REFERÊNCIAS BIBLIOGRÁFICAS}

CARVALHO, J.A.; HENRIQUES, E.B.; PAIVA, P.D.O.;
PEREIRA, G.M.; PEREIRA, J.R.D. Crescimento e produção de hastes florais de gladíolo cultivado com déficit hídrico nas diferentes fases fenológicas. Revista Brasileira de Horticultura Ornamental, Campinas, v.7, n.2, p.95-100, 2001.

FARIAS, M.F. de; SAAD, J.C.C.; BÔAS, R.L.V. Manejo da irrigação na cultura do crisântemo em vaso, cultivar Rage, cultivado em ambiente protegido. Engenharia Agrícola, Jaboticabal, v.24, n.1, p.51-56, 2004.

MATSUNAGA, M. Potencial da floricultura brasileira. Agroanalysis, Rio de Janeiro, v.15, n.9, p.56, set. 1995.

PAIVA, P.D. de O.; GUIMARÃES, R.J.; BERALDO, D.A. Efeito do número de linhas de plantio sobre a produtividade de gladíolo em cultivo intercalar à lavoura cafeeira. Revista Brasileira de Horticultura

Ornamental, Campinas, v.6, n.1/2, p.81-84, 2000.

PAIVA, P.D. de O.; SIMÕES, F.C.; VIEIRA, F.A. Cultura do gladíolo. Lavras: UFLA, 1999. (Boletim técnico. Serie extensão, 59). 